\title{
Characterisation of tree nut allergy in a population in a centre in the North of Portugal
}

\author{
Fabrícia Carolino ${ }^{1 *}$, Diana Silva ${ }^{1}$, Mariana Couto ${ }^{2}$, Alice Coimbra ${ }^{1}$, José Luís Plácido ${ }^{1}$ \\ From Food Allergy and Anaphylaxis Meeting 2014 \\ Dublin, Ireland. 9-11 October 2014
}

\section{Background}

Tree nuts and peanuts are among the major causes of food allergy (FA) in both children and adults. Crossreactivity is common among different nuts, but may also occur with peanuts, although they are unrelated foods. We aim to describe the prevalence and characteristics of tree nut allergy among children and adults followed in a University Hospital Allergy Department in the North of Portugal.

\section{Methods}

Medical records of patients studied in our Food Allergy Unit between Jan/2011 and Dec/2013 were reviewed; 134 children (55\% male; median age 7y [IQR 3-13y]) and 198 adults ( $24 \%$ male; median age 36y [IQR 2746y]) were studied for 194 and 315 suspected food allergic reactions, respectively. For those with suspected tree nut and/or peanut allergy, we recorded demographic characteristics, clinical history and study results based on sIgE, skin tests (ST), and oral food challenges (OFC).

\section{Results}

Fifty-two patients, 12 (9\%) children and 40 (20\%) adults, were referred for 65 suspected tree nut and/or peanut allergies (13\% of all reactions evaluated). FA to tree nuts was confirmed in 26 cases ( $73 \%$ adults), representing $8 \%$ of all patients studied, based on clinical history and positive $S T$ and/or $\operatorname{sIgE}(n=23)$ or positive OFC $(n=3)$. The main presentations were anaphylaxis in 13 cases ( $67 \%$ of the children vs. $47 \%$ adults, $\mathrm{p}=0.645$ ) and isolated mucocutaneous involvement in 12 cases $(33 \%$ vs. $53 \%, \mathrm{p}=0.645) ; 60 \%$ were immediate reactions. The main culprit was walnut in 11 cases and, in another 12, more than 1 tree nut was involved. The prevalence of atopy was $87 \%$ ( $83 \%$ children vs. $88 \%$ adults) and of asthma

${ }^{1}$ Serviço de Imunoalergologia, Centro Hospitalar São João, Porto, Portugal Full list of author information is available at the end of the article
$42 \%$. All 6 confirmed cases of peanut allergy were sensitized to at least one tree nut but, inversely, only 6 of the $26(23 \%)$ tree nut allergic were also sensitized to peanut.

\section{Conclusion}

The prevalence of tree nut allergy in the population studied in our Food Allergy Unit was of $8 \%$, predominantly affecting adults $(73 \%)$ and older children. No significant age-related differences were found. In this series, all peanut allergic individuals were also sensitized to nuts, but not the inverse. The majority of the reactions reported were severe.

\section{Authors' details}

${ }^{1}$ Serviço de Imunoalergologia, Centro Hospitalar São João, Porto, Portugal. ${ }^{2}$ Laboratório de Imunologia, Faculdade de Medicina, Universidade do Porto, Porto, Portugal.

Published: 30 March 2015

doi:10.1186/2045-7022-5-S3-P66

Cite this article as: Carolino et al: Characterisation of tree nut allergy in

a population in a centre in the North of Portugal. Clinical and

Translational Allergy 2015 5(Suppl 3):P66.

Submit your next manuscript to BioMed Central and take full advantage of:

- Convenient online submission

- Thorough peer review

- No space constraints or color figure charges

- Immediate publication on acceptance

- Inclusion in PubMed, CAS, Scopus and Google Scholar

- Research which is freely available for redistribution 